\title{
HISTÓRIA E LITERATURA: REFERÊNCIAS E IRREVERÊNCIAS
}

\author{
João Alfredo Dal Bello*
}

Não existe mais equilibrio, apenas rotatividade, exagero. É imposstvel dizer quem comanda a dança. Jean Baudrillard

problema da relação entre a escrita literária e a escrita da história tão velho quanto a estética - insiste em apresentar-se para debate, em todas as épocas, e sempre volta a lançar questões que lhe são inerentes: como criação literária e historiografia se enfrentam em relação ao objeto histórico, qual a identidade de cada discurso e quais suas singularidades? Dito de outra forma: para onde se dirige o olhar do literato ao manipular ficcionalmente o registro histórico, e o do historiador no seu fazer profissional? O que distingue profissionalmente um do outro, uma vez que ambos dão vida à matéria histórica do passado via representação na atualidade? Esta inquietação vem desde as primeiras manifestações literárias do mundo ocidental. É intrincada e intrigante a relação entre o estudo da história e o da literatura, e se torna mais aguda, num momento em que, no dizer de Christian Descamps,

* Universidade Federal do Paraná 
[a] irreverência científica avança sem precisar de ordens nem de um princípio de autoridade que a legitime. Nossa modernidade está reformulando as grandes questões filosóficas, a partir das interrogações mais sábias. É estimulante descobrir que há metafísica na física, poesia na matemática, desejo na história, filosofia na administração política e na economia. Essas rupturas, essas interfaces vão abalar vigorosamente os programas por demais acadêmicos. ${ }^{1}$

Essa "irreverência científica", além de questionar, por exemplo, as razões pelas quais a escritura historiográfica tradicional, marcada pela aproximação temporal do sujeito com o objeto de investigação, refutava a presença ficcional em seu relato, abre também espaço para um inter-relacionamento entre os diversos ramos do conhecimento, sem hegemonia de uns sobre outros. Cabenos, portanto, enfrentar a indispensável reflexão sobre os liames entre literatura e história e, num contexto de paradoxos - profícuos -, tentar balizar os campos. É o que pretende o presente trabalho, excerto de um estudo para tese: convocar vários pensadores para, estabelecendo o paralelo entre as diversas posições, examinar o estado atual da relação entre as duas escrituras.

Importa, de início, lançar um olhar sobre conceitos estabelecidos para, depois, dar lugar a novos pensamentos, que concedem aos saberes acesso a arriscadas - mas instigantes - aventuras interdisciplinares.

Edward Hallett Carr, em seu livro What is history? (1961), indaga no primeiro capítulo a relação entre o historiador e seus fatos. Busco seu auxílio para rastrear a questão. Carr retrocede ao século 19, afirmando ter sido uma época em que importavam os fatos isentos de imisção de qualquer ordem, consoante o aforismo cunhado por Ranke, na década de 1830, segundo o qual ao historiador competia tão-somente "mostrar como realmente foi" (wie es eigentlich gewesen). Esta máxima tornou-se, por três gerações, a palavra de ordem - uma espécie de encantamento - para historiadores alemães, ingleses e franceses, que os eximia da obrigação de pensar por si mesmos.

Os positivistas, ansiosos por ver a história como ciência, contribuíram para a intensificação do culto dos fatos, insistindo ser necessário, antes de mais nada, averiguá-los para, depois, extrair conclusões. A teoria empírica do conhecimento pressupõe uma completa separação entre sujeito e objeto. Fatos,

1 DESCAMPS, Christian. Entrevista concedida ao Le Monde. Idéias contemporâneas. São Paulo: Ática, 1989. p. 7-14. 
assim como percepções sensoriais, influenciam o observador de fora e são independentes de sua consciência. $O$ processo de recepção é passivo: após receber os dados, o observador passa a agir sobre eles. Assim, deve haver uma separação entre os dois processos: de um lado a experiência e de outro, bem distinta, a conclusão. Este é, segundo Carr, também o ponto de vista comum do que deva ser a história. Fatos são sagrados, opiniões são livres.

Contrapondo-se a tal linha de pensamento, o estudioso entende que do pesquisador da história deve-se, sem dúvida, esperar acurada observação do material que manipula, mas isso não se configura como uma virtude e sim, como obrigação: é condição necessária para seu trabalho; não, contudo, sua função essencial enquanto historiador. Os assim chamados fatos básicos, comuns a todos os historiadores, pertencem ao que ele chama de matéria-prima do historiador e não são história em si mesmos. Aliado a este entendimento, Carr observa que uma decisão a priori do historiador acompanha a seleção e o ordenamento daqueles fatos básicos. Refuta a opinião corrente de que os fatos falam por si mesmos: é na revisitação que lhes faz o historiador, na maneira como este os apresenta, num sistema seletivo de cognição, por ordem ou contexto, que eles começam a falar. Literalmente:

The historian is necessarily selective. The belief in a hard core of historical facts existing objectively and independently of the interpretation of the historian is a preposterous fallacy, but one which it is very hard to eradicate. ${ }^{2}$

Assim, a história que lemos, ainda que embasada em fatos, não é absolutamente factual, mas uma série de opiniões aceitas. $\mathrm{E}$ isto contraria frontalmente o conceito - ou fetichismo - vigente no século 19 de que a história consiste na compilação de um número máximo de fatos irrefutáveis e objetivos. Os documentos seriam a arca da aliança, no templo dos fatos, como se tudo que fosse aceitável e correto devesse respaldar-se por estar inserido em documentos, e, quanto mais deles, melhor. Carr vai adiante, afirmando:

No document can tell us more than what the author of the document thought - what he thought had happened, what he thought ought to happen or would happen, or perhaps only what he wanted others to think he thought, or even only what he

2 CARR, Edward Hallett. What is history? New York: Vintage Books, 1961. p. 10. 
himself thought he thought. [...] The facts, whether found in documents or not, have still to be processed by the historian before he can make any use of them: the use he makes of them is, if I may put it that way, the processing process. ${ }^{3}$

Gianni Vattimo, aliás, também nos adverte:

Não existe uma história única, existem sim imagens do passado propostas por pontos de vista diversos, e é ilusório pensar que existe um ponto de vista supremo, globalizante, capaz de unificar todos os outros. ${ }^{4}$

Voltando a Carr, no final de sua linha argumentativa, o estudioso faz eco à asseveração de Benedetto Croce, quando este declara que toda a história é história contemporânea, entendendo como o italiano que a história consiste essencialmente em ver o passado com os olhos do presente e à luz dos problemas da atualidade. Tarefa maior do historiador seria, então, não registrar, mas avaliar, porquanto se não desempenhar esta última tarefa, como poderia saber o que é digno de registro? Portanto, toda a história é história do pensamento. A reconstituição do passado, na mente do historiador, depende, contudo, de evidência empírica. Assim vistos, os fatos da história nunca chegam a nós "puros", porquanto envolvem a experiência do historiador e são refratados pela mente de quem os registrou. Dito de outra forma, o historiador interpreta em pensamento o que ocorreu na mente de suas dramatis personae, e o leitor, por sua vez, terá de reinterpretar o que se passou na mente do historiador. História significa, assim entendido, interpretação. Isto implica que o historiador deve dispor de compreensão e imaginação em relação às pessoas que estuda, que saiba inferir o pensamento subjacente aos seus atos. É necessário, no entanto, que essa compreensão imaginativa não se confunda com simpatia.

Continuando a exposição de seu pensamento a propósito da escrita da história, Carr ensina que

[...] we can view the past, and achieve our understanding of the past, only through the eyes of the present. The historian is of his own age, and is bound to it by the conditions of human existence.

3 CARR, op. cit., p. 16.

4 VATTIMO, Gianni. A sociedade transparente. Lisboa: Ediçōes 70, 1991. p. 11. 
The very words which he uses - words like democracy, empire, war, revolution - have current connotations from which he cannot divorce them. ${ }^{5}$

Nesse particular, o autor considera necessária uma observação: se o historiador enfoca o período histórico que estuda com olhos de quem vive em outro, o presente, e estuda os problemas do passado como chave para o conhecimento dos da atualidade, não incorreria em uma pura e simples pragmática visão dos fatos, sustentando, dessa forma, que o critério de uma interpretação correta seria sua conveniência a um propósito atual? Se assim for, adverte, os fatos da história nada são; a interpretação é tudo. Deverá, pois, o historiador ter em mente que ele nem é o humilde servo, nem o senhor tirano dos fatos. A relação entre ele e os fatos deverá pautar-se por uma serena reciprocidade, ou seja, seu fazer deverá deixar claro que não se configura como processo de moldagem dos fatos à interpretação, nem acomodação da interpretação aos fatos. E com essas considerações, Carr resume seu entendimento do que seja a história: "[...] it is a continuous process of interaction between the historian and his facts, an unending dialogue between the present and the past."6

Vejamos, a seguir, o que pensa Luiz Costa Lima a propósito da história e sua escrita. Resenhando Hayden White, Costa Lima afirma que o autor, pondo em discussão a identidade da escrita da história - dito mais explicitamente, sua cientificidade -, apóia-se no fato de que a concepção presente da história "legitima o historiador por seu trabalho sobre o fato ${ }_{3}$ sua fidedignidade, autenticidade e alocação em uma precisa linha temporal". ' Lido ao revés, a quimera ficcional afasta o historiador da veracidade dos fatos, ferindo o famoso lema de Ranke, acima mencionado, ou seja, de mostrar as coisas como foram, anulando o ego do narrador. Parece ter Ranke feito pia profissão de fé de que a Divina Providência se encarregaria de cuidar do significado da história, uma vez que ele se encarregasse dos fatos.

No entanto, para se enunciar o fato histórico é necessário o componente verbal. Mas como fazê-lo de forma que a linguagem, ao transmitir o conteúdo, seja transparente e não interfira em seu objeto? Essa indagação procede da evidência de que o campo de trabalho não é o mesmo das ciências puras matemática, por exemplo - onde se parte do suposto que a formulação não interfere significativamente no fenômeno descrito. A história, então, como a

5 CARR, op. cit., p. 28.

6 Ibid., p. 35.

7 COSTA LIMA, Luiz. Os bastidores da escrita da História. O Estado de S. Paulo, 8 abr. 1995. 
literatura, que não dispõe de linguagem transparente, está forçada à diversidade interpretativa, e esta passa a ser tomada como uma fraqueza que o historiador procura neutralizar pelo combate às interpretações opostas, esquecendo que a divergência estimula a flexibilização do juízo do receptor, a sua consideração de ângulos distintos.

Lamentando que a história só tem a perder em não considerar seu parentesco com a escrita literária, Costa Lima, convidando o leitor a não interpretar o silêncio de White a propósito das diferenças entre artefato histórico e literário como sinal de igualdade, aduz:

Haver laços de família entre a literatura e a escrita da História não impede, e o autor White não o negaria, que elas, modernamente, engendrem discursos diferentes. Não se interessar por sua diferença significaria que o autor a considera menos relevante?

O que White ensina é que temos duas construções verbais a serviço da representação, uma sobre fatos reais e outra sobre fatos imaginários.

O pensamento de Moses I. Finley, afinado com o de Carr, evidencia que todo trabalho histórico, em que pese a presença do passado, é um diálogo no presente e com o presente. Todos os nossos hábitos de pensamento, nossas associações de idéias, nossos valores são formados no presente e seria pretensão acreditar que podemos fugir deste e, a partir de uma tabula rasa, examinar o passado com absoluta "objetividade". Na verdade, a lidarmos com o passado teremos de lançar mão do imaginário, tanto na historiografia, quanto na criação literária. Seria por demais ousado pretender-se ler os registros historiográficos com uma consciência de que eles não foram "infectados" por sucessivas formas de resgate. E estas, obviamente, não são o próprio fato. As mencionadas formas de resgate tornam-se, portanto, permeáveis a valores que possuem suas próprias histórias. Disso se infere que temos todo o direito de desconfiar da objetividade da história, porquanto, ao figurar-se o real, há que se usar artifícios. Avesso à especialização excessiva, convoca Finley as outras ciências humanas em seu trabalho, como também o faz Carr, ao chamá-las de auxiliary sciences:

É um paradoxo, mas a história talvez seja a única atividade intelectual que não tem um objeto próprio. Talvez seja por isso que Aristóteles se recusava a considerar a história como uma 
épistèmê (hoje diríamos provavelmente uma "disciplina"), num capítulo célebre de sua Poética, em que ele recusa a história por não poder nos dizer nada além do que fez ou sofreu Alcebíades. Por consequência, o historiador deve apoiar-se constantemente nas outras ciências humanas: sociologia, economia, ciência política, antropologia, direito - é evidente - e também, se for o caso, psicologia, filosofia, lingüística, história da arte, crítica literária...

O ofício do historiador, como quer Finley, é estabelecer relações coerentes e, em consequiência, mais convincentes entre os fatos. Indispensável para o bom êxito da tarefa é que ele não dispense o instrumental que lhe alcançam outras disciplinas, entre estas a literatura. Admite, portanto, a interlocução entre as disciplinas. Antonio Medina Rodrigues, ao expressar-se sobre História antiga, do mesmo Finley, diz:

O autor entende que os fatos enfileirados no tempo decorrem de sistemas que o historiador deve construir, sem seguir o método de ninguém. Não parece poesia? Finley quer dizer que, enquanto o historiador constrói um mundo e o constrói por alargamento intuitivo dos fatos, ele, historiador, está fazendo uma coisa semelhante à que faz o poeta. Com a diferença, é claro, que os fatos induzidos pelo historiador devem obedecer a exigências mínimas de veracidade, ao passo que o poeta, ao fim e ao cabo, só se submete aos fatos que possam ser bem contados, vale dizer, contados com verossimilhança. ${ }^{10}$

Finley, nesta leitura, mostra-se cético quanto às fontes e admite a narração poética do fato histórico, o que o aproxima de Carr, White, Croce, antes mencionados, e de Humboldt.

Croce entendia ser necessário distinguir entre a arte em geral e a arte da história em particular, reservando para a primeira a intuição do possível e para a história a intuição do real, na linha do pensamento aristotélico: o objetivo de uma e outra é que as diferencia. Esta diferença entre arte e história se configuraria epistemologicamente, e não ontologicamente. Tanto o artista como o historiador

9 FINLEY, Moses I. Mito, memória e história. In: de Marylene Pinto Michael. São Paulo: Martins Fontes, 1989. p. 119.

10 RODRIGUES, Antonio Medina. Finley troca objetividade por narração histórica. $O$ Estado de S. Paulo, 30 abr. 1994. 
lidam com o fito de representar; aquele obedecendo a critérios de verossimilhança e este a critérios de verdade, mas ambos preocupados com o modo de construir convincentemente sua narração, conferindo-lhe integridade e consistência interna, o que, no entender de Croce, citado por White, garantirá credibilidade ao historiador-narrador:

Por isso é que o senso comum (buon senso) tem razão, contra os intelectualistas, de acreditar na história, que é, não uma "fábula convencionada", mas aquilo que o indivíduo e a humanidade recordam de seu passado. ${ }^{11}$

Também Croce assume que toda história é história contemporânea. Textualmente:

The practical requirements which underlie every historical judgement give to all history the character of "contemporary history' because, however remote in time events thus recounted may seem to be, the history in reality refers to present needs and present situations wherein those events vibrate. ${ }^{12}$

Quanto à concepção da representação da história para o historiador alemão Humboldt, diz White:

[...] Humboldt revelou as bases essencialmente clássicas e, em última análise, aristotélicas, de sua concepção do conhecimento histórico ao distinguir entre "idéias" num sentido estético, filosófico, e num sentido histórico. E o fez de modo a permitir a identificação do conhecimento histórico com o tipo de conhecimento que Aristóteles consignou especificamente à poesia. O tipo de entendimento que o historiador tem da realidade, argumentou, não é o tipo reivindicado pelo artista romântico, que é um conhecimento puramente subjetivo, ou uma expressão de um estado emocional subjetivo, mas sim uma apreensão do

11 WHITE, Hayden. Meta-historia: a imaginação histórica do século XIX. Trad. de José Laurênio de Melo. São Paulo: Edusp, 1992. p. 401 (Col. Ponta, 4).

12 CROCE, Benedetto. History as the story of liberty. London: George Allen \& Unwin, 1941.p. 19. 
mundo que poderia ter existido no interior dos acontecimentos que aparecem no registro histórico. ${ }^{13}$

Também Georges Duby, talvez o maior medievalista francês e admirável escritor, desconfia da objetividade da história e lembra ser ela inevitavelmente subjetiva e que todo discurso sobre o passado é engenho de um homem que vive no presente e que interpreta os vestígios do passado em função desse presente. Ao analisar o comportamento dos homens do passado, o historiador acaba também questionando a mentalidade do homem do presente. Para ele, os rastros deixados por um sonho não são menos reais do que os de um passo, e continua:

A realidade da informação contida nos vestígios de um castelo fortificado é tão grande quanto num poema vindo do imaginário de um homem da mesma época. Portanto, procuro interpretá-los da mesma maneira. ${ }^{14}$

Não existe racionalidade na história, segundo Duby; nela só encontramos inventividade, e é preciso escapar do maniqueísmo de ter que escolher entre o materialismo e o idealismo. Ele explica que, por recebermos informações oficiais, torna-se sobremodo difícil perceber, talvez nem tanto o entrecruzamento, mas o curso paralelo das histórias respectivas da economia, da política, da religião e da arte. É como se fosse uma série de filetes num fluxo contínuo, cada filete com seu próprio ritmo. Assim sendo, entende que

[o] trabalho do historiador consiste justamente em apreender as relações entre essas diversas instâncias do mesmo fenômeno. [...] A meu ver, para captar essas interferências, essas inter-relações, essas conexões, não devemos ser muito ambiciosos; é preciso tentar ter uma visão de conjunto de todos os diversos fenômenos, para conseguir estabelecer uma relação entre eles. A especialidade da ciência histórica é justamente estabelecer uma relação cronológica entre fenômenos distintos. ${ }^{15}$

13 WHITE, op. cit., p. 192.

14 DUBY, Georges. Entrevista concedida ao Le Monde. Idéias contemporâneas. São Paulo: Ática, 1989. p. 90-98.

15 Ibid., p. 92. 
No pensamento de Duby encontro um eco benjaminiano. Pensando em Walter Benjamin, Hannah Arendt, na sua brilhante coletânea de estudos sobre "homens em tempos sombrios", recorda que

[e]le estava interessado na correlação entre uma cena de rua, uma especulação na Bolsa de Valores, um poema, um pensamento, com a linha oculta que as une e permite ao historiador ou ao filólogo reconhecer que devem ser todos situados no mesmo período. [...] "era a tentativa de capturar o retrato da história nas representações mais insignificantes da realidade, por assim dizer, em suas raspas."

Ainda advogando a inventividade na história, encontramos o latinista que acabou por dedicar-se a ela, Paul Veyne. Ele insiste em que se dedicar à história é dar-se os meios de ter um recuo total, é tentar ter acesso à estranheza, ou seja, é impossível apreender a totalidade, logo não se pode pretender descrevê-la. Para o pensador o interesse de um livro de história não se encontra nas teorias, idéias e concepções da história que possam embasá-lo, mas na capacidade de tornar o passado "nem mais nem menos misterioso do que o momento em que nós vivemos". Interpretando o pensamento de Nietzsche ao questionar a vontade da verdade, não para soçobrar num relativismo sem interesse, mas para extrair as noções de perspectivas, ele assevera:

[...] na noção de verdade sempre se misturaram duas coisas: falar a verdade e a verdade das coisas. Não existe verdade das coisas. Não existe uma política que seria sempre a melhor, a verdadeira, a única sensata e que condenaria todo o resto a ser apenas uma palhaçada. A inventividade permanente condena todas as nossas pequenas racionalidades. $O$ que não quer dizer que se deva aceitar tudo. Quer dizer que não existe uma única regra e que devemos nos arranjar para encontrar soluções. Por isso, afirmo que não existe uma verdade das coisas, mas que um historiador pode dizer a verdade. ${ }^{17}$

16 ARENDT, Hannah. Homens em tempos sombrios. São Paulo: Companhia das Letras, 1987. p. 142.

17 VEYNE, Paul. Entrevista concedida ao Le Monde. Idéias contemporaneas. São Paulo: Ática, 1989. p. 151-160. 
Em belo estudo do pensamento de Veyne, Francisco Moraes Paz assim se expressa:

\begin{abstract}
[...] lembremos com Paul Veyne, a verdade nāo é o principal valor do conhecimento. Ter idéias é mais importante que conhecer verdades. Parafraseando-o, temos que uma história está bem morta quando a defendemos em vez de inventá-la. Não obstante o debate sobre o fim da história, vemos o revigoramento de suas energias utópicas através da constatação da polissemia dos sentidos, da exploração de estratos simbólicos mais profundos. Seu inventário explicativo aposta naquilo que há de social nos homens, de cultural nos indivíduos e grupos, de real nas representações. Não poderia ser diferente. Diante de um novo fin-desiècle, sob o efeito dos mass media, assistimos à multiplicação generalizada de visões de mundo. De visões de história. ${ }^{18}$
\end{abstract}

Para estear o entendimento que norteia este trabalho no aspecto da possível aproximação da literatura à história, convoco Benedito Nunes. Nunes, rastreando o pensamento de Ricoeur, argumenta que, ao se intentar tal abordagem, há de ser levado em máxima consideração o aspecto tempo tanto para o acontecimento como para seu relato. Segundo o estudioso,

[n]arrar é contar uma história, e contar uma história é desenrolar a experiência humana do tempo. A narrativa ficcional pode fazê-lo alterando o tempo cronológico por intermédio das variações imaginativas que a estrutura auto-reflexiva de seu discurso the possibilita, dada a diferença entre o plano do enunciado e o plano da enunciação. A narrativa histórica desenrola-o por força da mímesis, em que implica a claboração do tempo histórico, ligando o tempo natural ao cronológico.

A narração, contudo, não recria o fato; este foi único no tempo. O que a leitura pode fazer é refigurar tal tempo. Nunes ensina que ao lermos uma obra

18 PAZ, Francisco Moraes. História e pós-modernidade. In: SEMINÁRIO CULTURA E SOCIEDADE: A CRISE DOS MODELOS. Curitiba. s.n.t. (inédito), p. 8.

19 NUNES, Benedito. Narrativa histórica e narrativa ficcional. In: RIEDEL, Dirce Cortes (Org.). Narrativa: ficção c história. Rio de Janeiro: Imago, 1988. p. 9-35. 
historiográfica ativamos as potências imaginativas da figuração para tornar visível o passado. A imaginação se faz visionária.

A leitura, portanto, ficcionaliza a História. Em contrapartida, a leitura historiciza a Ficção, na medida em que a voz narrativa situa no passado o mundo da obra. É, pois, na refiguração do tempo que a narrativa histórica e a narrativa ficcional se interpenetram, sem se confundirem. [...] pode-se concluir que as duas epistemologias, a da História-Ciência e a da História-Arte [...] se complementam na base do tronco narrativo comum que também une, como formas simbólicas similares do pensamento, História e Ficção. ${ }^{20}$

Por fim, o nome de Luiz Costa Lima é sempre lembrado ao serem examinados os pontos de identidade e de distinção dessas duas formas discursivas. Ele mostra que a marca diferencial entre os dois discursos é a convenção de veracidade que deve reger a escritura da história; já a literatura não concede foros de verdade àquilo que declara, ou seja, "dentro da moldura do 'teatro mental', o poeta não documenta suas conviç̧ões ou valores ao falar das saudades por um marinheiro ou ao tomar um criminoso, um asceta ou um marginal como seu herói". ${ }^{21}$ Enquanto discurso ou formação discursiva específica, afirma Costa Lima, é próprio da literatura o caráter não documental, uma radicalidade não documental. Ele se configura não como prova, documento, testemunho do que aconteceu, "porquanto o que nele está se mescla com o que poderia ter havido; o que nele há se combina com o desejo de que estivesse; e que por isso passa a haver e a estar". ${ }^{22}$ É por essa razão que se há de dar à literatura um tratamento que não é compativel com o documento. Quanto a este, não é senão um material primeiro para o historiador, que deverá filtrá-lo e coordená-lo. Adverte ainda que o uso do documento afeta a própria natureza do documentado, porque aquele se torna vulnerável ao tipo de interpretação que se lhe empresta. Encontro nas palavras do estudioso uma síntese do entendimento da questão:

O problema da história como "ciência" consiste no estatuto das interpretações que ela oferece. Já no caso do estudo da literatura

20 NUNES, op. cit., p. 34-35.

21 COSTA LIMA, Luiz. Sociedade e discurso ficcional. Rio de Janeiro: Guanabara, 1986. p. 193.

22 Ibid., p. 195. 
o documento apresenta um status radicalmente diverso. [...] Dadas essas considerações, podemos então concluir: ao passo que o documento desempenha um papel decisivo na pesquisa histórica, na análise do discurso literário ele é um elemento secundário; secundário não significa que possa ser dispensado, mas apenas que $o$ analista deve ter consciência da impossibilidade de, a partir dele, inferir a configuração do teatro mental que forma o seu objeto.

Expostos os diferentes enfoques no tratamento da questão, encontro um ponto de convergência entre os estudos mais atuais: eles concordam que cada discurso tem sua identidade e tarefa, o que, contudo, não levanta barreira ao seu inter-relacionamento.

Parece que se deve dar a César o que é de César e a Deus o que é de Deus para que os dois senhores nos brindem com um diálogo de parceiros.

\section{RESUMO}

O problema da escrita literária e a escrita da história apresenta-se para debate, em todas as épocas, e sempre volta a lançar questões que lhe são inerentes: como historiografia e criação literária se enfrentam em relação ao objeto histórico, qual a identidade de cada discurso e quais suas singularidades. Este trabalho enfoca a relação entre os dois campos de estudo.

Palavras-chave: literatura e história, interdisciplinaridade, ficção e historiografia. 


\section{ABSTRACT}

The problem of literary versus historical writing has always been under discussion and each time it raises issues such as the approach that historiography and literary creation take in relation to the historical object, the identity of each type of discourse and their peculiarities. This paper deals with the relationship between both fields of interest.

Key words: literature and history, interdisciplinarity, fiction and historiography.

\section{REFERÊNCIAS BIBLIOGRÁFICAS}

ARENDT, Hannah. Homens em tempos sombrios. São Paulo: Companhia das Letras, 1987.

CARR, Edward Hallett. What is history? New York: Vintage Books, 1961. . Sociedade e discurso ficcional. Rio de Janeiro: Guanabara, 1986.

COSTA LIMA, Luiz. Os bastidores da escrita da história. O Estado de S. Paulo, 8 abr. 1995.

. Sociedade e discurso ficcional. Rio de Janeiro: Guanabara, 1986. p 193.

CROCE, Benedetto. History as the story of liberty. London: George Allen \& Unwin, 1941.

DESCAMPS, Christian. Entrevista concedida ao Le Monde. Idéias contemporâneas. São Paulo: Ática, 1989. p. 90-98.

DUBY, Georges. Entrevista concedida ao Le Monde. Idéias contemporâneas. São Paulo: Ática, 1989. p.90-98.

FINLEY, Moses I. Mito, memória e história, In: . Uso e abuso da história. Trad. de Marylene Pinto Michael. São Paulo: Martins Fontes, 1989.

NUNES, Benedito. Narrativa histórica e narrativa ficcional. I $n$ : RIEDEL, Dirce Cortes (Org.). Narrativa: ficção e história. Rio de Janeiro: Imago, 1988. p. 9-35.

PAZ, Francisco Moraes. História e pós-modernidade. In: SEMINÁRIO CULTURA E SOCIEDADE: A CRISE DOS MODELOS. Curitiba. s.n.t. (inédito)

RODRIGUES, Antonio Medina. Finley troca objetividade por narração histórica. $O$ Estado de S. Paulo, 30 abr. 1994.

VATTIMO, Gianni. A sociedade transparente. Lisboa: Edições 70, 1991.

VEYNE, Paul. Entrevista concedida ao Le Monde. Idéias contemporâneas. São Paulo: Ática, 1989. p. 151-160.

WHITE, Hayden. Meta-história: a imaginação histórica do século XIX. Trad. de José Laurênio de Melo. São Paulo: Edusp, 1992. (Col. Ponta, 4). 